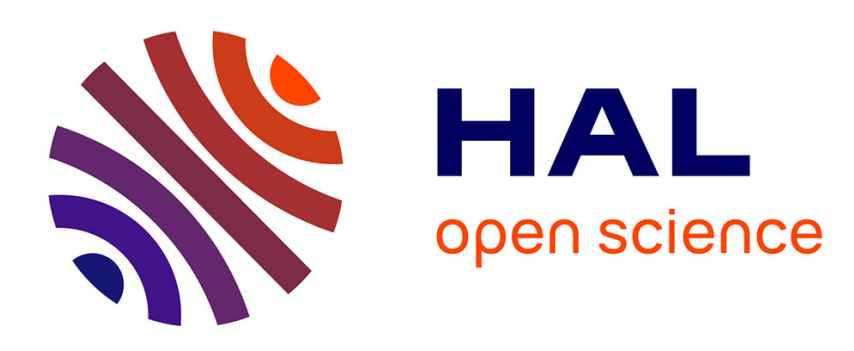

\title{
Hard Constraints: Why Telemanipulated Surgical Robots Affect Creative Tool Use
}

Ignacio Avellino

\section{To cite this version:}

Ignacio Avellino. Hard Constraints: Why Telemanipulated Surgical Robots Affect Creative Tool Use. WISH@CHI19 Symposium: Workgroup on Interactive Systems in Health, May 2019, Glasgow, United Kingdom. hal-02145432

\section{HAL Id: hal-02145432 https://hal.science/hal-02145432}

Submitted on 6 Jun 2019

HAL is a multi-disciplinary open access archive for the deposit and dissemination of scientific research documents, whether they are published or not. The documents may come from teaching and research institutions in France or abroad, or from public or private research centers.
L'archive ouverte pluridisciplinaire $\mathbf{H A L}$, est destinée au dépôt et à la diffusion de documents scientifiques de niveau recherche, publiés ou non, émanant des établissements d'enseignement et de recherche français ou étrangers, des laboratoires publics ou privés. 


\section{Hard Constraints: Why Telemanipulated Surgical Robots Affect Creative Tool Use}

\section{Ignacio Avellino}

Sorbonne Université, CNRS, ISIR

Paris, France

ignacio.avellino@sorbonne-universite.com

\section{Keywords}

creativity, surgical robots, teleoperation,

appropiation

\begin{abstract}
The operating room is fertile ground for creativity: problems constantly arise, various surgical tasks impose their own constraints, and a wide range of tools is available. The introduction of telemanipulated robots in Minimally Invasive Surgery (MIS) has impacted the work of surgeons and their teams in terms of communication, use of perceptual senses, social structure, roles, and more. But do they also impact creativity? I present preliminary results of data re-analysis from an earlier field study focusing on creative tool use. Results suggest that current surgical robots limit creativity as they impose hard constraints: they remove haptic feedback, isolate the surgeon, and are built in rigid ways.
\end{abstract}

Permission to make digital or hard copies of part or all of this work for personal or classroom use is granted without fee provided that copies are not made or distributed for profit or commercial advantage and that copies bear this notice and the full citation on the first page. Copyrights for third-party components of this work must be honored. For all other uses, contact the owner/author(s).

WISH'19 Poster, CHI 2019 Conference on Human Factors in Computing Systems

May 4-9, 2019, Glasgow, Scotland UK,

๑) 2019 Copyright held by the owner/author(s). 


\section{INTRODUCTION}

The introduction of telemanipulated surgical robots has greatly impacted the work of surgical teams. In a field study [1] I observed that surgeons sit behind a console far from their team and patient. As a result, they gain autonomy, as they can assist their own gestures, but they pay the price of being socially secluded, of an impoverished communication with their teams, of losing perceptual senses, such as haptic feedback from tools, and, of burdening the bedside assistant with the role of technical assistant to the robotic arms. But do telemanipulated robots also affect creativity?

I re-analyze data from this field study with a focus on creative tool use. I report on examples of creativity in classic MIS and reflect on why surgeons are not as creative in robotic-assisted MIS.

\section{BACKGROUND}

Creativity has been defined in different ways, although authors agree that it requires both originality and effectiveness [11]. In other words, creativity is novelty that has value. Constraints play a generative role on creativity, with some authors going as far as saying that what is not constrained, is not creative [6]. But the role of constraints is dual, both limiting and enabling it: without constraints, the creative process becomes borderless and impossible to evaluate, and with too rigid constrains the creative processes becomes too limited [9].

Coadaptation is a phenomenon where people adapt their behavior to the available technology and they adapt the technology to their own needs [7]. This process entails creativity, as people adapt technology in unexpected ways to the designer for the practical purpose of solving a problem.

Minimally Invasive Surgery (MIS) is a type of procedure where surgeons open small holes on patients to insert trocars, tubular devices that let inserting and removing tools while restricting air flow. Surgeons use elongated mechanical instruments to operate and an endoscope to see inside the body through a 2D monitor. The clinical benefits of using small incisions include reduced pain, hospital stay, discomfort, and a quicker return to work [3]. MIS is no stranger to creativity, as in this environment there is constant problem solving and each surgical tasks impose a different set of constraints. Moreover, the large and diverse set of available tools creates opportunities for appropriation.

Robotic-assisted MIS aims at overcoming the shortcomings of classic MIS and has the potential of bringing opportunities that go beyond human limits, such as extreme precision. Today, the da Vinci system [5] is the market leader. It is a teleoperated system where the surgeon sits at a console and manipulates joysticks that control robotic arms inserted in the patient. 

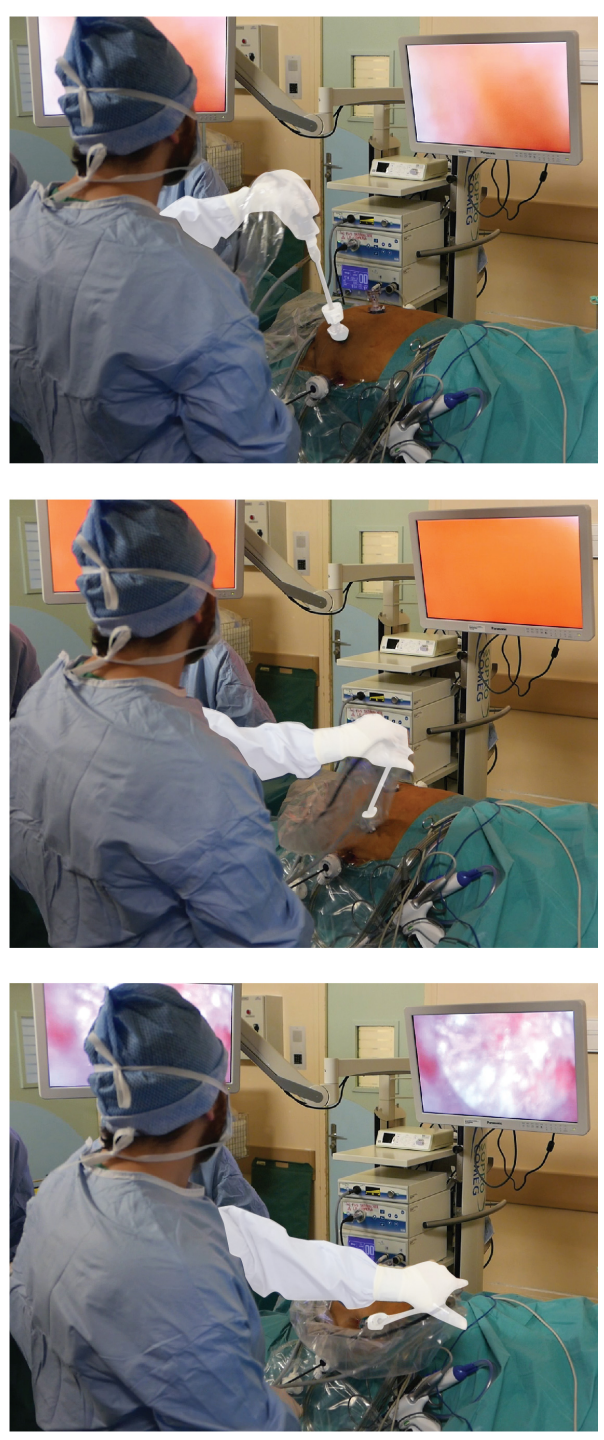

Figure 1: Dissecting Tissue with the Camera Shaft. The surgeon uses the endoscope as a lever to pull tissue apart.
Creativity in surgery has always existed, surgeons have historically been creative practitioners in their craft since its origin [10]. Tool appropriation as an example of creativity has already been recognized in surgery. Gauderer acknowledged this while delivering the Robert E. Gross lecture: "New uses for existing instruments, adaptations and modifications of established procedures, and changes in the flow of information in the clinic or the wards are all examples of creativity" [4]. He also presents several personal creative moments which involve tool use, for instance using a catheter to access to the stomach during laparoscopy, which later became a standard method for gastrostomy. In Spencer's [12] presidential address (reported in [2]), he similarly explains that creativity is stimulated by the surgeon, the environment and the idea, including its origin, development, and clinical application. The environment includes the available tools that can be used in unexpected ways.

As interactive systems in healthcare are part of the tools available to surgeons, they play a role in enabling or limiting creativity.

\section{FIELD STUDY}

I re-analyze a previously conducted field study on the impacts of telemanipulation in robotic assisted surgery [1], focusing now on creative tool use. For details on the methodology readers can refer to the original publication. The results from this data analysis are preliminary as further interviews with surgeons are need to probe deeper into the creative use of tools. Data Collection consisted in observing (21) and video-recording (14) surgeries, along with conducting interviews (12) with surgeons, nurses and medical interns. Data Analysis consisted in watching videos and identifying creative tool use, defined as use beyond its intended purpose to solve a problem. I first present four cases of creative tool use, and later discuss why surgical robots limit appropriation and creativity.

\section{Preliminary Results in Creative Tool Use}

1. Dissecting Tissue with the Camera Shaft. During paraaortic lymphadenectomy (removal of the paraaortic lymph nodes), surgeons spend long periods of time dissecting tissue both to create the working space inside the patient and to find the nodes. The tools normally used for this task are bipolar forceps and monopolar scissors, yet in this study, two surgeons used the endoscope shaft to dissect tissue. Because the endoscope is a long and solid beam that goes through a pivoting point, it has the same affordances as a lever (Figure 1). Moreover, the force surgeons apply on the proximal end is multiplied on the distal end, a phenomenon called the fulcrum effect [8], making it more powerful when dissecting tissue. This situation took place when the more experienced surgeon was holding the endoscope, sometimes because $\mathrm{s} / \mathrm{he}$ was acting as an assistant. In one other occasion during the study, one surgeon used the port's distal end in the same way to dissect tissue. Appropriating the endoscope as a dissecting tool is a creative tool use deriving from the problem of having to break hard tissue with the constraint of not removing the endoscope. 

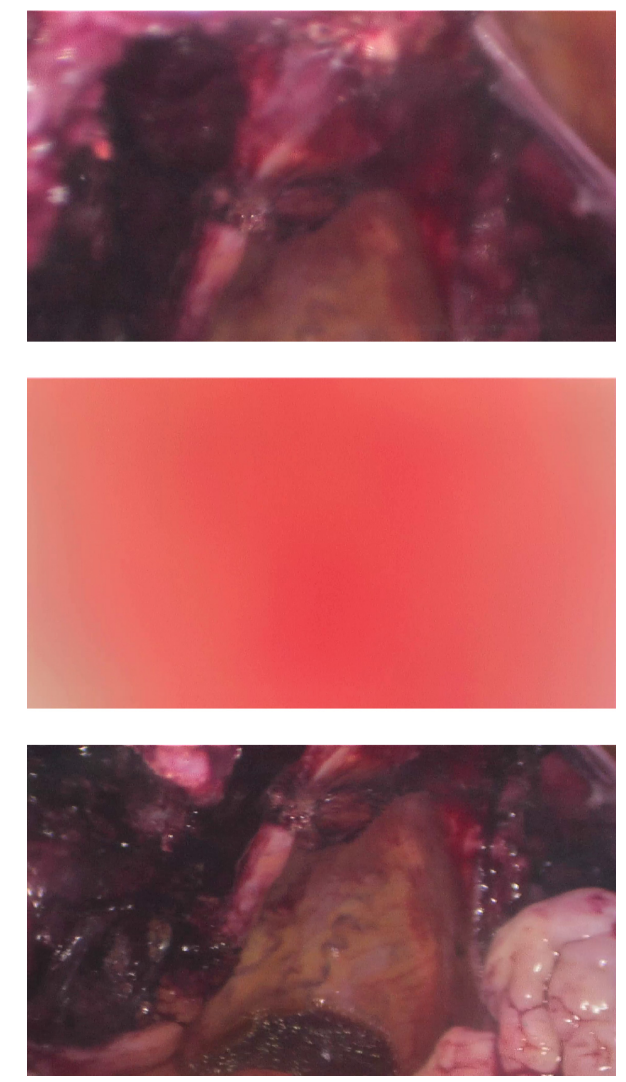

Figure 2: Cleaning the Endoscope by Rubbing It Against Human Tissue: endoscopic image before (foggy), during and after rubbing the endoscopy against tissue.
2. Exposing the Surgical Site Using the Endoscope Shaft. Exposition is when structures have to be moved aside as the surgical site is located behind an organ or in a cramped area. To expose, an assistant normally uses the grasper tool to hold an organ and advances the endoscope so that the surgeon can advance both surgical tools and operate. During the field study, surgeons that were highly experienced took over for exposition and at times used the endoscope shaft to push an organ sideways while at the same time sliding the endoscope behind the structure, avoiding making the tip dirty. Once more, the endoscope is used as a lever because of its properties. Appropriating the endoscope as an exposition tool is a creative tool use deriving from the problem of having to push organs away with the constraint of not removing the endoscope and also keeping it clean.

3. Cleaning the Endoscope by Rubbing It Against Human Tissue. Debris such as tissue and blood often dirty the endoscope. The endoscope is then removed from the body and cleaned by rubbing it against a sterile gauze or glove, or by inserting it into a thermos that contains warm water with a gauze at the bottom for rubbing. This causes setbacks because it both interrupts the surgical task and adds to the total surgery duration. In this study, at least three surgeons regularly cleaned the endoscope by rubbing it against tissue inside the patient. They would prefer to rub against tissue (Figure 2) that will be removed as part of the surgery such as the uterus in a total hysterectomy for security reasons: if the tissue is accidentally pierced as a result of applying too much force, the damaged tissue will be removed anyways. Appropriating human tissue as a surface to rub off debris from the endoscope is a creative use of a surface deriving from the problem of cleaning the endoscope, again, with the constraint of not removing it from the body.

4. Transillumination for Pointing. Transilumination consists on glowing light through tissue to differentiate inner structures, as each structure reflects light in a particular way. For example, surgeons shine the endoscope light from the inside towards the outside of the skin to identify blood vessels and other structures that should be avoided when piercing a trocar. During interviews, two surgeons reported that they use transilumination to point at specific locations such that bedside assistants can interpret deictic instructions. Most notably, when an experienced surgeon asks an assistant to insert a trocar or a needle through the skin, s/he pushes the endoscope from the inside towards the skin wall to indicate the insertion point, while giving the instruction to insert a trocar. Appropriating the endoscope as a pointing device is a creative tool use deriving from the problem of pointing during deictic instructions, with the constraint of not using the hands, as this requires letting go of the tools. 


\section{DISCUSSION}

The creative moments observed in this study were only observed during classic MIS, deriving from having to solve problems under the constraint of working inside the body without letting go of tools. I believe these creative moments did not not happen during robotic-assisted MIS as, most notably, they could only happen under certain conditions: in all the examples surgeons relied on haptic feedback as they needed to feel how much force they applied on tissue to avoid damaging it; and in the transilumination example in particular, both the surgeon and the assistant relied on having a direct view of the patient as they needed to see the light shining through the skin.

Creativity thrives when constraints are not too lose, not too tight [9], this study suggests that the current telemanipulated paradigm for surgery imposes hard constraints that limit creativity by removing haptic feedback from direct tool manipulation as well as the direct sight of the patient. In particular for the da Vinci robot, its rigid design also contributes towards limiting tool appropriation: only the components from one manufacturer can be used, which does not allow for mix and matching tools through defined interfaces as in classic MIS; and, modularity is low, for instance surgeons cannot rearrange the pedals on the console according to their preference nor customize the joysticks.

It might be the case however that rigidity is purposely in the design to avoid the risk of accidents from unintended use. One future challenge for surgical robots will be to consider appropriation in their design while keeping safety a priority. Further studies are needed to investigate how the constraints that surgical robots impose could lead to new forms of creativity. It might be too early for appropriation to emerge as the tool is fairly new and surgeons may have not yet reached a level of mastery that allows them to break the rules it imposes.

As in the previous analysis [1], I question the choice of a telemanipulated approach. Teleoperation is not a necessary condition for robotic surgery as the increase in dexterity and precision can be achieved while having the surgeon operate robotic tools directly with their hands, next to the patient.

\section{STUDY LIMITATIONS}

Firstly, this is a preliminary study on creativity in MIS. More observations are needed to identify more creative moments and to continue shaping the arguments in this article. Moreover, interviews are needed to continue the exploration on the explanations for these behaviors.

\section{CONCLUSION}

This short article explores appropriation of tools in creative ways during minimally invasive surgery, and how teleoperated surgical robots, an type of interactive system for healthcare in full in booming development, possibly limit such creativity. Future surgical robots will be faced with the challenge of designing for appropriation while keeping safety central. 


\section{ACKNOWLEDGMENTS}

This research was supported by the Labex CAMI (project ANR-11-LABX-0004) operated by the ANR as part of the program "Investissement d'Avenir". We thank all the participants of this study for their valuable time.

\section{REFERENCES}

[1] I. Avellino, G. Bailly, G. Canlorbe, J. Belghiti, G. Morel, and M.-A. Vitrani. Impacts of Telemanipulation in Robotic Assisted Surgery. In (to appear) CHI Conference on Human Factors in Computing Systems Proceedings (CHI 2019), CHI '19, New York, NY, USA, May 2019. ACM.

[2] A. DeAnda and A. C. Galloway. Historical perspectives of The American Association for Thoracic Surgery: Frank C. Spencer. The Journal of Thoracic and Cardiovascular Surgery, 145(4):906-908, Apr. 2013.

[3] N. Fuchs Weizman, R. Maurer, J. I. Einarsson, A. F. Vitonis, and S. L. Cohen. Survey on Barriers to Adoption of Laparoscopic Surgery. Journal of Surgical Education, 72(5):985-994, Oct. 2015.

[4] M. W. L. Gauderer. Creativity and the surgeon. Journal of Pediatric Surgery, 44(1):13-20, Jan. 2009.

[5] G. S. Guthart and J. K. Salisbury. The Intuitive(TM) telesurgery system: overview and application. In Proceedings 2000 ICRA. Millennium Conference. IEEE International Conference on Robotics and Automation. Symposia Proceedings (Cat. No.00CH37065), volume 1, pages 618-621 vol.1, San Francisco, CA, USA, Apr. 2000. IEEE.

[6] P. N. Johnson-Laird. Freedom and constraint in creativity. The nature of creativity: Contemporary psychological perspectives, 202, 1988.

[7] W. E. Mackay. Responding to cognitive overload: Co-adaptation between users and technology. Intellectica, 30:177-193, 2000

[8] I. Nisky, F. Huang, A. Milstein, C. M. Pugh, F. A. Mussa-ivaldi, and A. Karniel. Perception of Stiffness in Laparoscopy âĂŞ the Fulcrum Effect. Studies in health technology and informatics, 173:313-319, 2012

[9] B. Onarheim and S. Wiltschnig. Opening and Constraining: Constraints and Their Role in Creative Processes. In Proceedings of the 1st DESIRE Network Conference on Creativity and Innovation in Design, DESIRE '10, pages 83-89, Lancaster, UK, UK, 2010. Desire Network. event-place: Aarhus, Denmark.

[10] D. J. Riskin, M. T. Longaker, M. Gertner, and T. M. Krummel. Innovation in Surgery. Annals of Surgery, 244(5):686-693, Nov. 2006.

[11] M. A. Runco and G. J. Jaeger. The Standard Definition of Creativity. Creativity Research Journal, 24(1):92-96, Jan. 2012.

[12] F. C. Spencer. Presidential address. Intellectual creativity in thoracic surgeons. The Journal of thoracic and cardiovascular surgery, 86(2):163-179, Aug. 1983 